\title{
Use of Saps in Concrete as Internal Curing Agent
}

\author{
AniketDilipraoPatil, Kishore Ravande
}

\begin{abstract}
-assuaging of sturdy expect a critical pastime within the development of cohesion and electricity of bond. As in step with IS concrete obtains the structure nice after 28 days of actual reestablishing, which improves the microstructure, achieves thick concrete. Indian fashions says the water required for reestablishing ought to be consumable and in copious symbolize fulfill the hydration essentials. The hard difficulty in excessive caliber or low w/c volume concrete is prolonged tendency of encountering internal parting at early age. even as this breaking won't deal the compressive nature of those kinds of bond, yet willing to offers their complete deal energy. The inward breaking may be the impact of autogenous shrinkage happened in mild of self-evaporating which takes place normally in the course of hydration underneath not completely doused or constant situations. along those lines, career of reestablishing lies in reducing water disappearing from concrete and to keep up satisfactory water content internal sturdy, that is essential for the hydration of the safety, and bond microstructure development, pore structure, and houses. SAPs have excessive water ingestion residences; this makes them mainly charming in association with cement. This paper will give the audit on utilization of SAPs in concrete to obtain catastrophe porosity, better pleasant, much less mass adversity, higher modulus of adaptability, high parting limit, and so on.
\end{abstract}

Watchwords-w/c quantity, mass adversity, autogenous shrinkage, volumetric water maintenance, cut up obstacle, water vulnerability.

\section{INTRODUCTION}

In the existence of robust, water has a few imperative noteworthiness:

- it's miles large solving within the arranging, alleviating and bracing of concrete;

- Harden concrete may swell, analyst, and likely break up; with exchange of water with enveloping.

- Its closeness in robust effect high-quality and creep.

It expect a rule paintings in disintegrating found out independent from some other person drying, water permeability or chloride assault. Unmistakably, manage of water is primary to concrete. [1]

This paper offers a review of a bit of the open entryways presented by using superabsorbent polymers (SAPs) in bond for accomplishing extra water manage.[1] SAPs are polymer materials on the way to in fashionable ingest an considerable share of water from the earth and hold it into their structure. [2] SAPs in the main made for protection of watery recreation plans and, occasionally; they will have a water digestion point of confinement of numerous occasions their own weight. popular, cutting-edge first-rate SAPs commonly have a water upkeep of 100 to $400 \mathrm{gm} / \mathrm{gm}$ of dry, and that they may be made in any form and size. SAPs is going below the social affair of indicated "wise substances"; materials that, in a managed way, they could trade their homes intently taking after an external condition. [3] by means of and big SAPs swells after they ingest the water and experts reversibly provided to drying. This belongings made SAPs at risk to use concerning concrete. using SAPs basically decrease the wealth water applied in establishing their by way of making one walk toward viable development development. determine 1 beneath gives notion with reference to how the temperature of the strong consciousness decreases with the extension of SAPs.

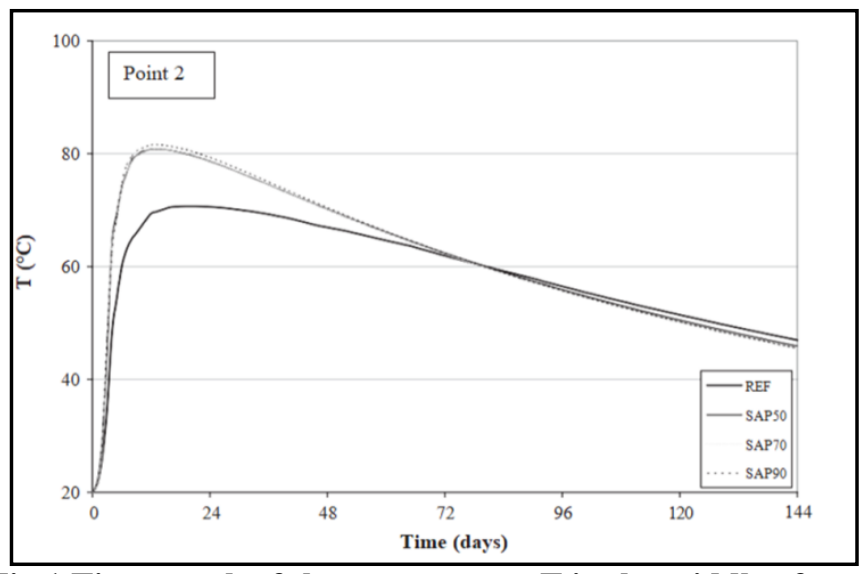

Fig.1.Time graph of the temperature $T$ in the middle of the bridge deck [1]

\section{AUTOGENOUS SHRINKAGE}

Autogenous shrinkage happens because of the selfdesiccation of the fresh concrete (with low w/c-ratio, there's a loss of water at some stage in the cement hydration).[2] Self desiccation of concrete reasons long time shrinkage due to decrease inside the inner humidity for the duration of hydration method. alternatively chemical shrinkage is because of reduction within the area which hydration products don't take after hydration completes. [2] there are numerous varieties of shrinkage may also come into account but only autogenous shrinkage is fundamental at early a long time. excessive-overall performance concrete (HPC) with low w/c-ratio regularly develops a low permeability. therefore, it's miles assumed that external curing techniques

Revised Manuscript Received on 16 September, 2019.

AniketDilipraoPatil, Assistant Professor at Civil Engieeering, MIT School of Engineering, MIT ADT UNIVERSITY, Pune, Maharashtra, India.(Email: aniket.patil@mituniversity.edu.in)

Kishore Ravande, Professor at Civil Engineering, Principal,MIT School of Engineering, MIT ADT UNIVERSITY, Pune, Maharashtra, India.(Email: kishore.ravande@mituniversity.edu.in). 


\section{Use Of Saps In Concrete As Internal Curing Agent}

aren't effective for self-desiccation of concrete at the middle of the contributors. on this regards imparting an inner curing will assist to keep the additional water inner concrete required for hydration of the cement and considerably reduces self-desiccation [3].

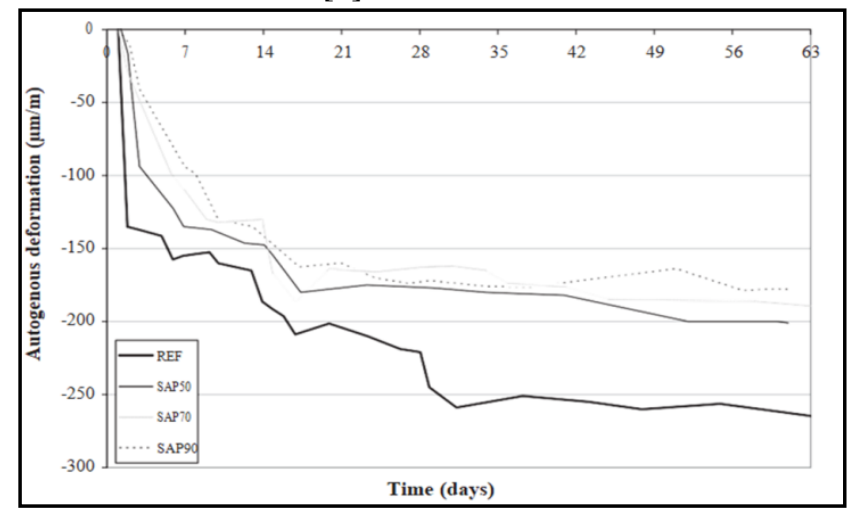

Fig.2. Mitigation of the long term deformation by adding SAPs.[1]

A. figure 2 suggests headway of the autogenousmisshapening graph plotted at an age of sixty one days. The autogenous shrinkage is $262 \mu \mathrm{m} / \mathrm{m}, 201 \mu \mathrm{m} / \mathrm{m}$, $190 \mu \mathrm{m} / \mathrm{m}$ and $178 \mu \mathrm{m} / \mathrm{m}$ for independently REF, SAP50, SAP70 and SAP90.[1] there was rarely decline inside the shrinkage in view of usage of SAPs anyway full decline illogical in any of the above mixes. [1]

\section{II. have an impact on ON fine}

From a first-rate point of view, the extension of SAPs to bond has two converse consequences: Too retentive polymer makes voids inside the robust and they diminishes fine. at the opposite facet inner water reestablishing given through the SAP extends the degree of hydration and suggests prolonged pleasant. Which of those two results is overpowering relies upon upon the w/c volume $(\mathrm{w} / \mathrm{c})$, the proportion of SAP protected and the development of the concrete.[2] If SAP blanketed at a high w/c (>0.forty five), has no effect on hydration and thusly generally reduces compressive satisfactory. on the contrary aspect at a low w/c (<0.forty five), might also enlarge the compressive exceptional.[2]

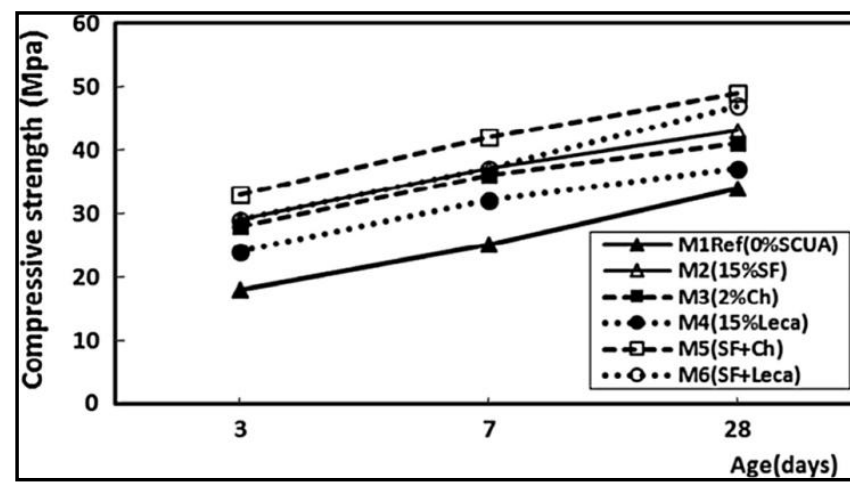

Fig.3. Effect of self-curing agent type on compressive strength of concrete (air curing at 250C) [2]

Fig. 1 exhibits that, the compressive nature of the widespread variety of mixes (fashionable and selfreestablished) extended consistently after extension of SAP at air assuaging (250C). this is an aftereffect of self- reestablishing operators' serves to continuation of hydration system inside bond. moreover choices of SAP lower pores and voids and provide remarkable retaining among sums and strong paste. [2]

\section{MODULUS OF Versatility}

The progression of younger's Modulus of adaptability have shown equal instance as compressive quality for oneself reestablished mixes. in any case, the robustness augments faster than the quality after three days. It become visible that eighty five \% of electricity is beginning at now accomplished within the robust at 28 years of age days. [1] but including higher percentage of SAPs shows decline inside the modulus of pliability. Regardless, the discount isn't always for all intents and functions indistinguishable as decline inside the tractable and compressive satisfactory. [1]

The modulus of adaptability of every single robust mix (self-alleviated and popular concretes) extended a tiny bit at a time as confirmed up within the fig.4. the use of Leca as inner reestablishing professional exhibited fantastic results and extended modulus of flexibleness differentiated and the ordinary bond.

The proportionate extended results have been checked whether there need to be an occasion of polyethylene glycol as self-reestablishing grasp. Leca and polyethylene glycol exhibited $4 \%$ and three.five $\%$ extension in the modulus of adaptability while appeared differently in relation to traditional concrete at 28 years of age days.

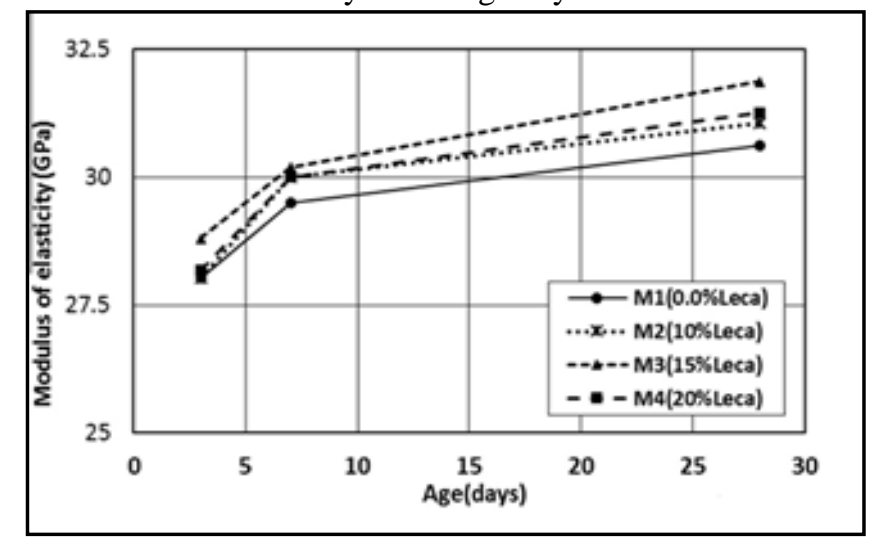

Fig.4. Effect of saturated Leca \% on Modulus of Elasticity of Self Curing Concrete[5]

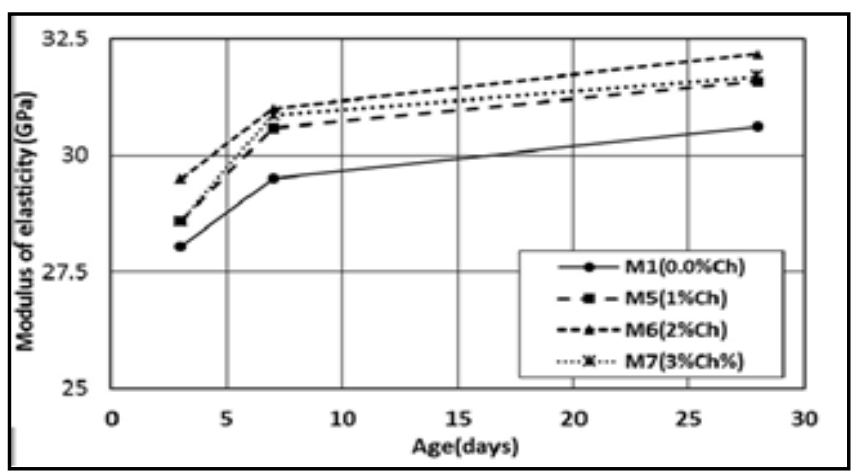

Fig.5. Effect of polyethylene glycol ch \% on Modulus of Elasticity of Self Curing Concrete [5]

Published By:

Blue Eyes Intelligence Engineering

\& Sciences Publication 


\section{MASS LOSS}

Fig. 6-9 illustrates that the mass lack of all concrete mixes (self- cured and conventional concretes) containing Leca and $\mathrm{ch}$. as internal curing retailers. $10 \%$ Leca has confirmed less mass loss in comparison to $15 \%$ and $20 \%$ addition and conventional concrete on the age of 28 days. then again, it may be seen that the use of different percentages of Ch. (1$3 \%$ ) significantly reduces the mass loss and provide higher water retention. With addition of $1 \%, 1.5 \%$ and a couple of $\%$ of ch.has reduced the mass loss substantially which shows that $2 \%$ is the highest quality dosage of $\mathrm{ch}$.

it's far determined that better w/c ration purpose better mass loss and same is relevant within the case of cement. higher quantity of cement produces excessive amount of warmth of hydration which bring about the evaporation of water from concrete inflicting better amount of mass loss. So it's miles found that discount in both cement and water can show better reduction within the mass loss. using silica fume along sidech. to confirmed better effects in mass loss than conventional concrete. [6]

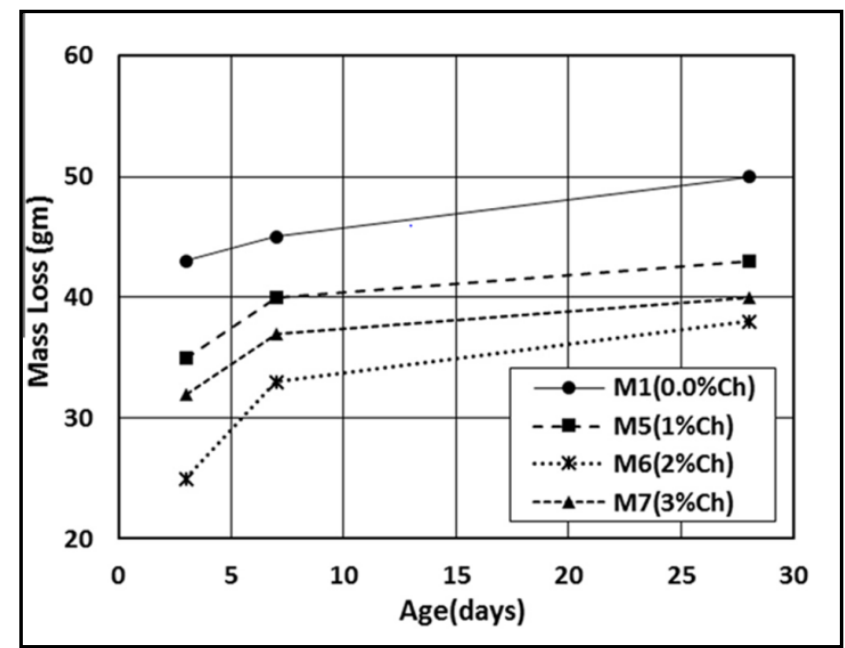

Fig.6. Effect of polyethylene glycol \% on mass loss. [6]

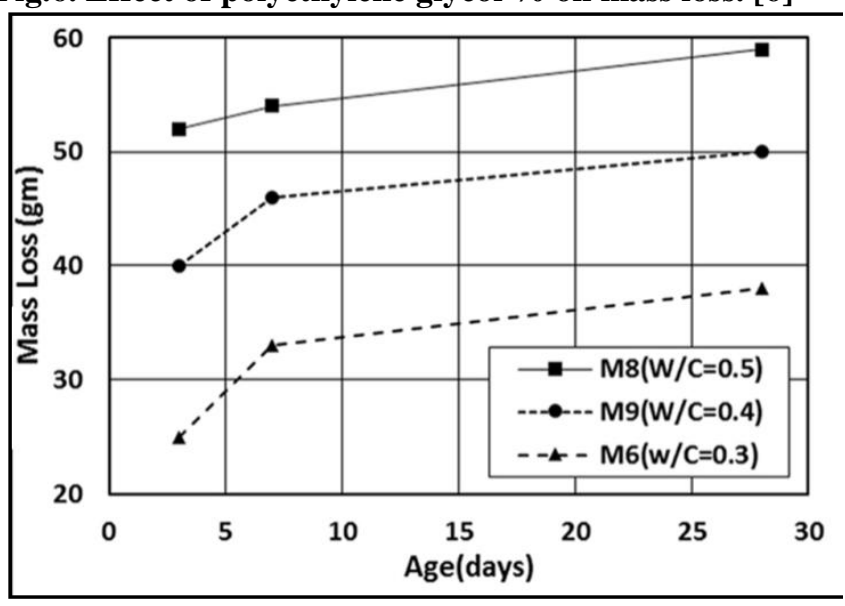

Fig.7. Effect of water cement ratio on mass loss. [6]

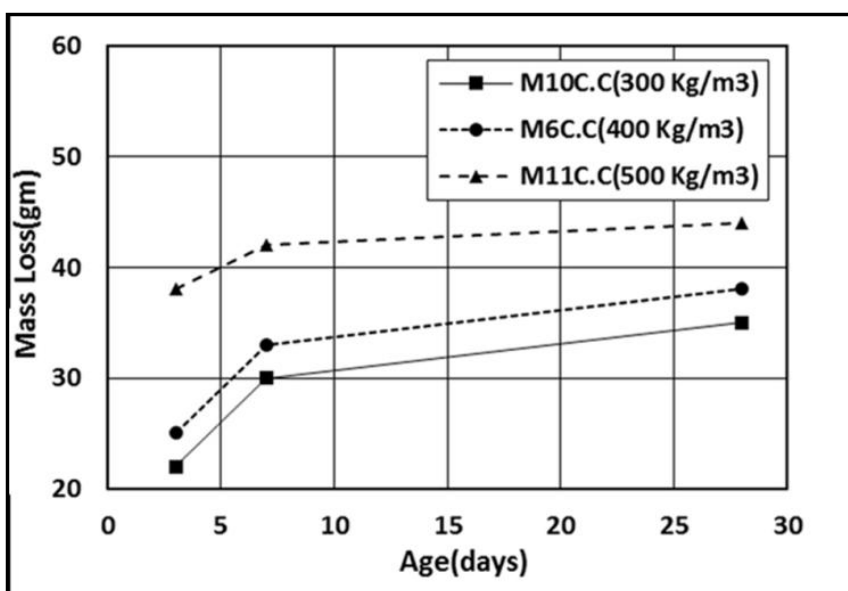

Fig.8. Effect of cement content on mass loss. (Concrete with $2 \%$ ch) [6]

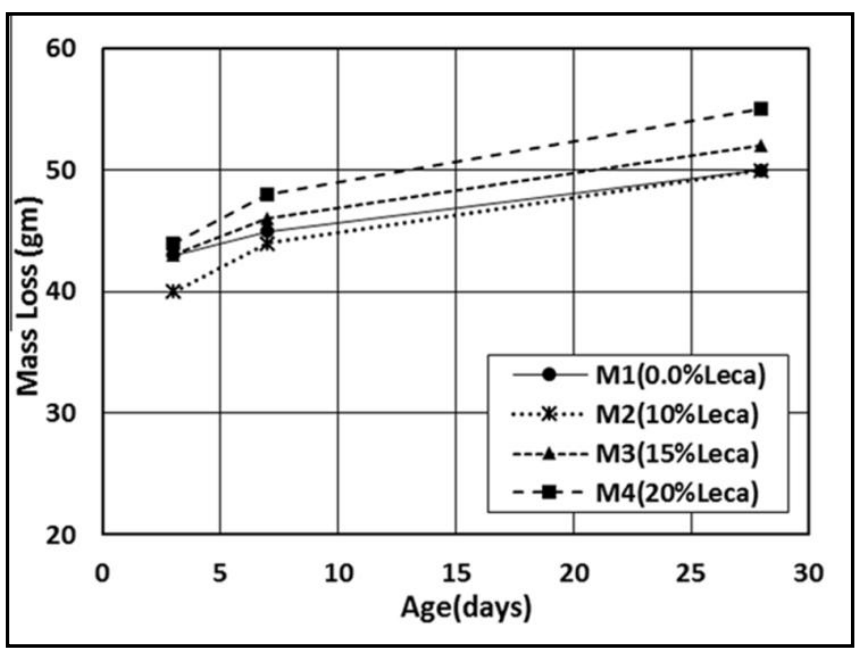

Fig.9. Effect of Leca \% on mass loss. [6]

\section{III.VOLUMETRIC WATER ABSORPTION}

Fig. 10 uncovers that the volumetric water assimilation is higher for the w/c percent zero.five. that means bring down the w/c percentage will lessen the volumetric water ingestion at 28 years vintage days. it's miles located that utilizing leca up to fifteen\% indicated higher bring about volumetric water retention approximately $8 \%$ at 28 years vintage days that is $0 \%$ for traditional cement. then again usage of ch. In cement lessens the dissipation of interior water which gives progressively thick and void unfastened concrete at 28 years antique days. utilization of ch. Up to two $\%$ emerge as indicated nearly same effects in volumetric water retention even as contrasted with ordinary cement. 


\section{Use Of Saps In Concrete As Internal Curing Agent}

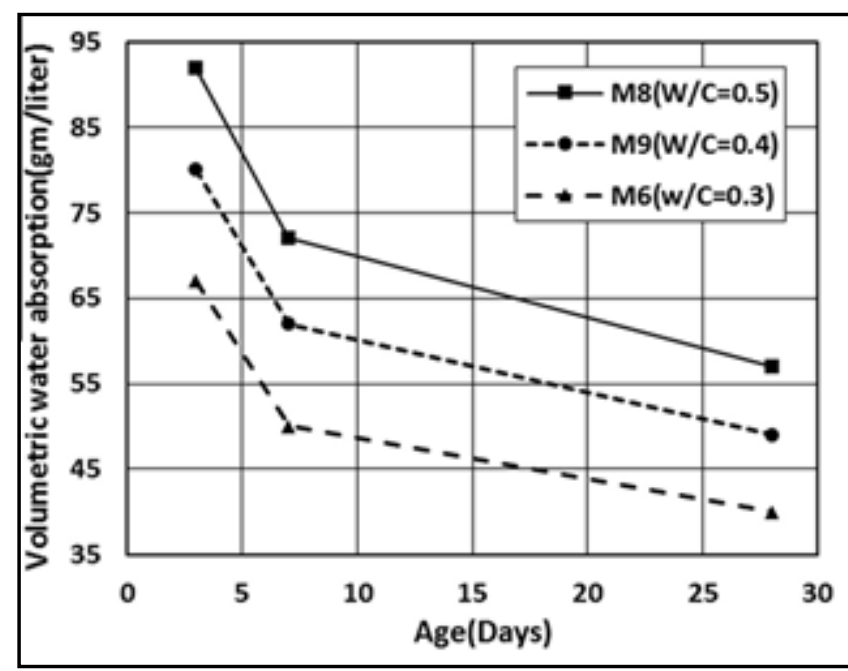

Fig.10. Effect of w/c on volumetric water absorption of concrete $(2 \% \mathrm{ch})[6]$

\section{IV.WATER PERMEABILITY}

- Determine 11 and 12 demonstrates the aftereffects of water penetrability of cement with and without overly permeable polymers. Cement consists of polyethylene glycol has favored outcome over normal cement for all extents. Better consequences were seen at $2 \%$ measurements of polyethylene glycol than special mixes.

- Concrete with $10 \%$ leca has validated the maximum minimum outcomes for water penetrability and for distinctive extents indicated desired effects over standard cement.

- As degree of leca builds no. Of pores will increments and which suggests higher estimations of water penetrability than lower extents.

expansion of SAPs offers thick concrete with less degree of water porousness at 28 years vintage days.

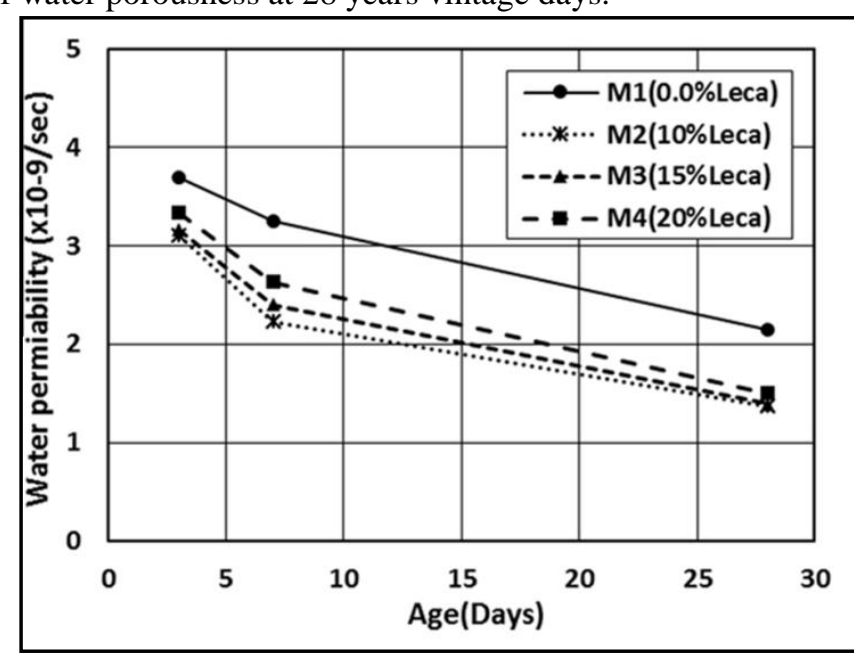

Fig.11. Effect of leca\% on water permeability coefficient.

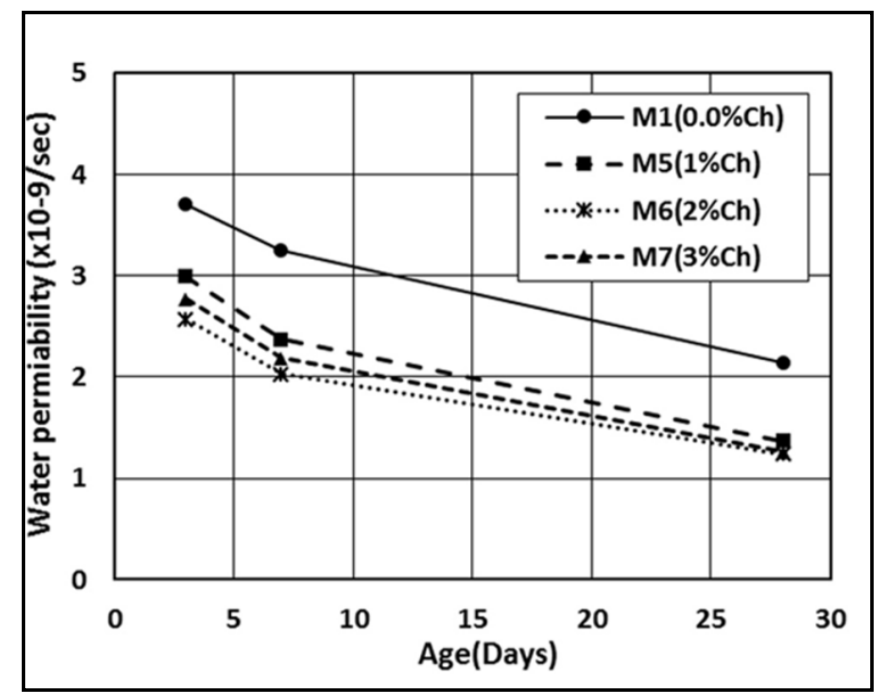

Fig.12. Effect of ch \% on water permeability coefficient.

\section{V.CRACK RESISTANCE \& PATTERN\& RESULTS}

The crack patterns of internal curing concrete at $24 \mathrm{~h}$ after casting are shown in Fig. 13. As can be seen from Fig. 13a, an extended crack regarded on the floor of the reference concrete $(\mathrm{C}-\mathrm{c})$. As for other specimens with SAP, the duration of cracks has turn out to be short and the distribution regions emerge as small. consequently, it could be observed that SAP has successfully averted the length and quantity of cracks. The volume and one of a kind modes of entrained water of SAP have also affected the crack sample notably. the quantity of cracks has decreased with the boom of quantity. similarly, compared to different modes of entrained water of SAP, the crack distribution is extra dispersive and the period of the cracks has emerge as quick while pre-absorbed SAP is used. For the concrete with unabsorbed SAP, the initial cracking time of concrete increases gradually, the cracking width decreases glaringly, and the cracking place additionally decreases notably with the boom of volume. This suggests that the unabsorbed SAP reduces the crack width and cracking region efficaciously, and delays the initial cracking time of concrete. The effect of SAP on cracking width and cracking area is specifically fantastic. 


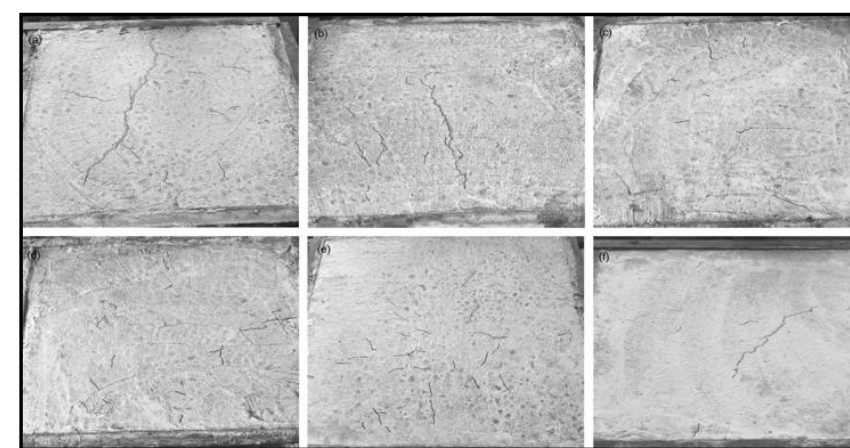

Fig.13. Crack morphology of concrete with use of SAPs.[9]

For regular power and high electricity concrete it is better to apply PEG600 than PEG400 as chemical internal curing. PEG400 \& PEG600 has capacity to retain water internal concrete which reduces the evaporation of moisture from concrete to surrounding. [10]

Figs. $14 \& 15$ display the crack pattern for excessiveenergy beams. It become observed that the concrete with PEG400 shows fewer cracks as compared with PEG600 and Leca. [10]

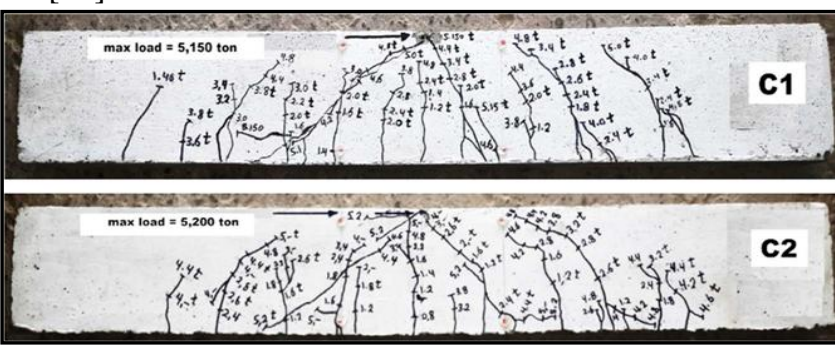

Fig.14.Crack pattern for control beam. [10]

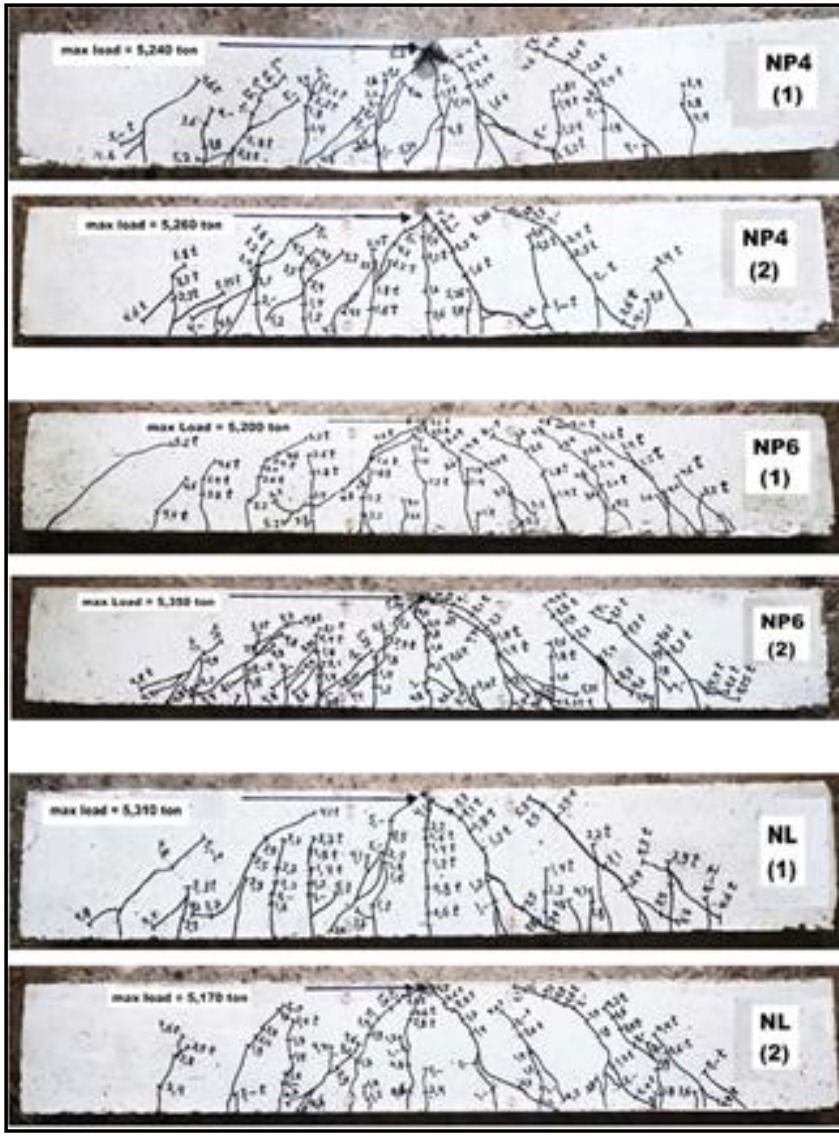

Fig. 15. Crack pattern for high strength SAP based concrete. [10]

\section{VI.CONCLUSIONS}

As referenced inside the introduction, SAPs have mind blowing water preservation characteristics; this makes them for the most component fascinating in association with cement. due to the water renovation, Overly Permeable Polymers can likewise further be taken into consideration as a way to oversee porosity, that's every different boundless matters for bond. Following are more than one closures depending upon above consequences and assessment:

- Very retentive polymers like Sodium polyacrylate may be carried out in dry or clammy circumstance to keep a key suitable approaches from the early age breaking of concrete. full decline in autogenous shrinkage is beyond the universe of creative thoughts.

- SAPs can build the compressive pleasant at abatement w/c extents, however critical reduction is visible in compressive super at higher w/c share.

Modulus of adaptability of concrete may likewise augmentation as much as certain percentage of broadening of SAPs anyway it'll decrease as percentage of SAPs stretched out over one in every of a type traits.

- In casa of mass adversity, higher estimations of SAPs and bond display higher mass mishap. at the off danger that unique level of SAPs secured mix with silica smoke will decrease the mass catastrophe.

- growth of polyethylene-glycol (Ch.) Into solid mixes lessens the dissemination of soddenness inside sturdy, which allows a ceaseless hydration method, actuates a notably much less porous, thick and extra restrained bond than conventional concrete.

- Including Saps In To Stable Presentation Notably Less Water Permeability While Appeared Differently When It Comes To Regular Manipulate Concrete.

- split venture of the solid with saps is notably advanced than normal bond. Development of saps can manage the spoil time period, width and parting version. Much less share of elements apparent through using saps when stood out from manipulate concrete.

\section{REFERENCES}

. Bart Craeye , Matthew Geirnaert, Geert De Schutter, "Overly keeping polymers as an internal mitigating administrator for solace of early-age breaking of first class stable augmentation decks", development and constructing materials 25, PP-1-13, 2011.

2. O. Mejlhede Jensen, "usage of Superabsorbent Polymers in Concrete", A chart of the feasible effects exhibited by using strategies for making use of these sharp substances as sturdy admixtures, ppforty nine-fifty two, January 2013 Cement broad.

3. Magda I. Mousa, Mohamed G. Mahdy, Ahmed H. Abdel-Reheem, Akram Z. Yehia, "Self-assuaging strong sorts; water protection and solidness", Alexandria Designing Diary fifty four, pp-565-575,2015.

4. M Venkateswarlu, V balajirainbow, M Susmitha and D Suresh, "focus on strength Attributes of regular Cement with PEG-600 as Self Restoring Compound", eu Diary of Advances in Designing and Innovation, 2(12): forty seven-fifty two. 2015. 


\section{Use Of Saps In Concrete As Internal Curing Agent}

5. Magda I. Mousa, Mohamed G. Mahdy, Ahmed H. Abdel-Reheem, Akram Z. Yehia, "Mechanical places of self-reestablishing concrete (SCUC)", HBRC Diary eleven, 311-320, 2015.

6. Magda I. Mousa, Mohamed G. Mahdy, Ahmed H. Abdel-Reheem, Akram Z. Yehia, "bodily properties of self-reestablishing concrete (SCUC), HBRC Diary eleven, 167-a hundred 75, 2015.

7. Fazhou Wang, Jin Yang, Hua Cheng, Jing Wu, and Xiongyi Liang, " deal with device of Desorption conduct of Immersed Superabsorbent Polymers in Concrete" ACI materials Diary, 112-M44, 463-470, might also-June 2015.

8. VeluSaraswathy, SubbiahKarthick, Han Seung Lee, Seung-Jun Kwon, and Hyun-Min Yang, "near research of harmony and consumption safe homes of undeniable and mixed Bond Concrete sorts", Advances in materials science and Designing extent, Article identification 9454982, 2017

9. Juntao Dan, Jun Zhao, Wei Miao, Zhaohua Du, "effect of superabsorbent polymer on the shrinkage and cut up deterrent of bond at early age", Iranian Polymer Diary, 27:349-358, 2018.

10. M.M. Kamala, M.A. Safana, A.A. Bashandya,*, A.M. Khalilb, "check assessment at the lead of customary lovely and excessive notable selfreestablishing self-compacting sturdy", Diary of structure Designing 16, pp-79-ninety three, 2018.

11. Sung-Hoon Kang, Sung-Gul Hong, Juhyuk Moon, "Shrinkage attributes of heat managed extremely-tip pinnacle bond and its balance making use of superabsorbent polymer essentially primarily based internal alleviating method", Bond and stable Composites 89 , pp-a hundred thirty-138, (2018).

12. Sung-Hoon Kang, Sung-Gul Hong, Juhyuk Moon, "The impact of superabsorbent polymer on thrilling size of pore shape in pretty first elegance robust", improvement and building substances 172, pp-2940, (2018).

13. A.S. El-Dieb, T.A. El-Maaddawy, "Appraisal of help admission assurance of self-diminishing strong", Diary of shape Designing 20, pp-seventy two-80, (2018).

14. Huamei Yang, Ph.D., Zhen He, Yixin Shao and Lei Li, Ph.D. "enhancing prevent Defrost Obstruction and excellent boom of roller Compacted Fly Fiery remains Cements with modified Permeable Polymer" J. Mater. Civ. Eng., , 30(three): 04018010, 2018.

15. ChristofSchröfl, Viktor Mechtcherine, Michaela Gorges, "Relation between the molecular structure and the efficiency of superabsorbent polymers (SAP) as concrete admixture to mitigate autogenous shrinkage", Cement and Concrete Research 42, 865-873 (2012) 